\title{
LITRACON: A STATE-OF-THE-ART REVIEW
}

\author{
Kusuma Sahithi \\ Structural Engineering, Jawaharlal Nehru \\ Technological University, Hyderabad \\ Telangana, India
}

\author{
Pulletikurti Mouunica \\ Structural Engineering, Jawaharlal Nehru \\ Technological University, Hyderabad \\ Telangana, India
}

\begin{abstract}
This state-of-the-art review discusses the development in the use of the transparent concrete and its application in energy saving and artistic finish. The need of smart construction techniques to satisfy the structure in safety monitoring (such as damage detection, fire warning) and environmental protection is arising day-by-day. Translucent concrete (Transparent concrete or Light Transmitting Concrete (Litracon)), is new type of concrete different from normal concrete. It is the combination of optical fibers and concrete. Optical fiber is a transmission element, which decreases the use of artificial light. The normal concrete is replaced by translucent concrete, which has natural lighting and art design. Translucent concrete allows more light and less weight compared to normal concrete. The use of natural source of light(sunlight) instead of using electrical energy is the main purpose of translucent concrete, to reduce the load on nonrenewable sources and result, it into the energy savings.
\end{abstract}

Keywords- Transparent Concrete, Optical Fibers, Energy saving, Artistic Finish

\section{INTRODUCTION}

Concrete has an important role in the development of infrastructure. Due to rapid population growth, small buildings are replaced by high rise buildings. This arises the problem in deriving natural light in building due to obstruction of nearby structures. An innovation like "Light Transmitting Concrete (LiTraCon)," transmits sunlight into buildings, which could reduce our dependence on artificial sources and save resources. The LiTraCon mainly focuses on transparency and its objective of application pertains to green technology and artistic finish.

Hungarian architect, Aron Losonczi, first introduced the idea of light transmitting concrete in 2001 and then successfully produced the first translucent concrete block in 2003, named Litracon. Litracon (Light Transmitting Concrete) is a cement based material which includes cement, fine aggregate, optical fiber and water. Its light transmitting properties depends on the large numbers of optical fibers as strands which transmit the light through the fine concrete. Optical fiber used in fine concrete may be plastic, glassy or organic fiber. It transmits light which may be natural or artificial from one end of concrete element to another end.

Gurupreet Singh et al. (2016) investigated that the transmission of light through Litracon cube depends upon percentage of optical fiber used on the surface area. Initial cost of Litracon is more compared to conventional concrete but on duration of time, it is concluded for its reduction of energy consumption.

Ravikumar.N et al. (2018) investigated that the compressive strength of concrete block reduces with the increase in percentage of fibers (i.e. the percentage of surface area of concrete block) used in the concrete block. The compressive strength reduces for more than $4 \%$ of optical fibers and hence optimum is about $3 \%$ of optical fibers.

\section{MATERIALS USED}

1) Cement : No special cement is required. Ordinary Portland cement can be used.

2) Fine Aggregate : Sand passing through $1.18 \mathrm{~mm}$ size sieve should be used.

3) Water: Water is used for mixing all the constituents of concrete.

4) Optical fiber : An optical fiber is a flexible, transparent fiber made from glass (silica) or plastic. There are three layers of an optical fiber i.e. core, cladding and coating.

Core - It is thin glass center of the fiber in which the light travels.

Cladding - It is the outer optical material surrounding the core which reflects the light back into the 
core. To restrict the reflection in the core, the refractive index of the core must be more than that of the cladding. Coating - It is the plastic coating which protects the fibers from damage and moisture.

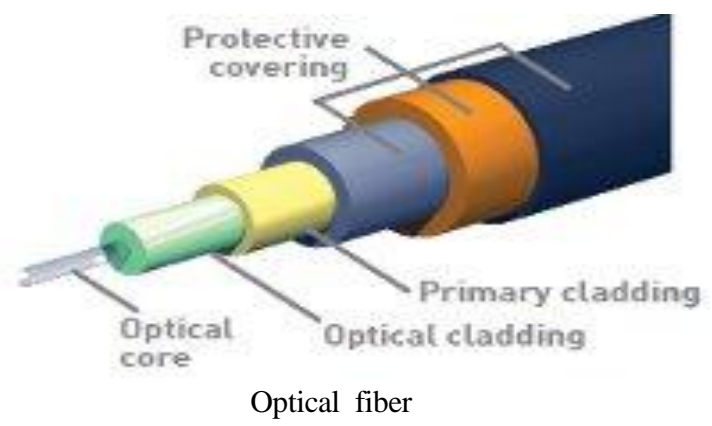

\section{PRINCIPLE}

Transparent concrete is a work based on "NanoOptics." When light traveling in an optically dense medium hits the boundary at a steep angle (larger than the critical angle for the boundary), the light is completely reflected. This is called total internal reflection. This effect is used in optical fibers to confine light in the core.

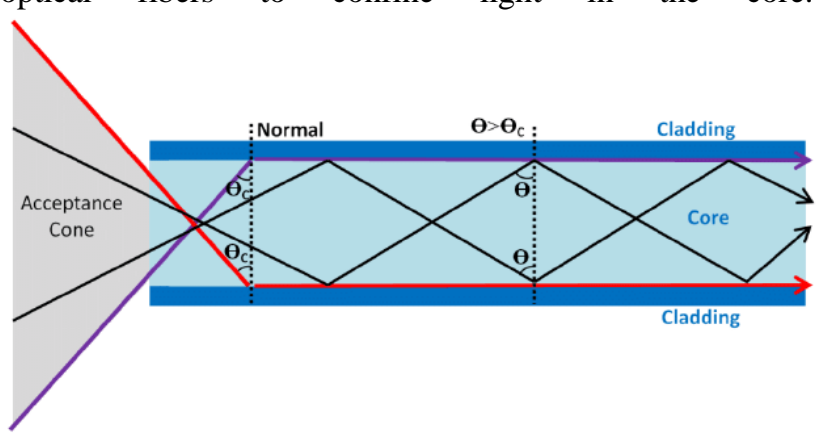

Total Internal Reflections in an Optical fiber

\section{METHODOLOGY}

\section{A) Preparation of the Mould-}

A mould of size $150 \mathrm{~mm} * 150 \mathrm{~mm} * 150 \mathrm{~mm}$ is prepared with wood as shown in Fig.(1). Place the clay or mud in the sides where the optical fibers are exposed to the mould for easy demoulding.

\section{$B$ ) Fixing the Fibers-}

The cleavage of the mould is done very carefully as per the optical fiber size. The diameters of optical fiber which are commonly available are $0.25 \mathrm{~mm}, 0.5 \mathrm{~mm}, 0.75$ $\mathrm{mm}, 1 \mathrm{~mm}$, and $2 \mathrm{~mm}$.
Fibers are usually placed in layer distribution so that they provide good reflection properties. Several holes are driven on the mould so that optical fibers can pass through them in an organized manner. The fibers run parallel to each other, transmitting light between two surfaces of the concrete element, in which they are embedded as shown in Fig.(2).

\section{C) Concreting-}

As optical fibers are inserted first in the mould through holes provided in mould, the concreting is done very carefully so that it does not disturb the optical fibers. For obtaining the good compaction, the concrete is filled in thinner layers. Also a needle vibrator is used to avoid the voids' formation in concrete block as shown in Fig.(3).

\section{D) Removing the Mould-}

The mould is removed after 24 hours. The casted mould is placed on leveled surface then it is de-moulded carefully.

\section{E) Cutting and polishing-}

The extra fibers can be cut as per the size of the mould. Finally the polishing is done with the help of sand paper or some polishing paper.

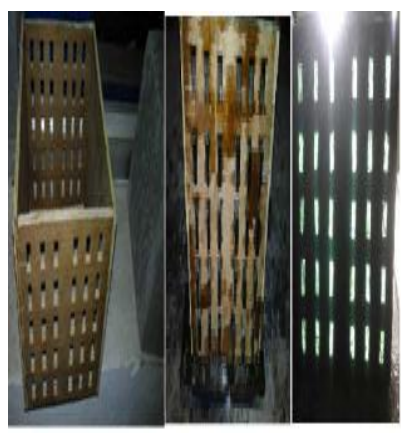

Fig.(1)

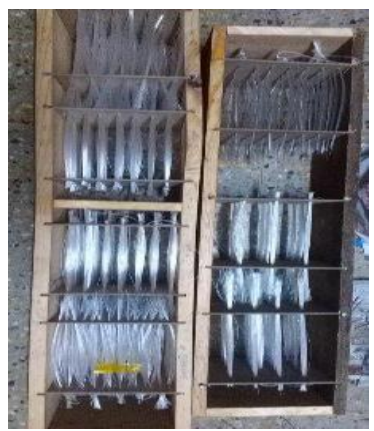

Fig.(2)

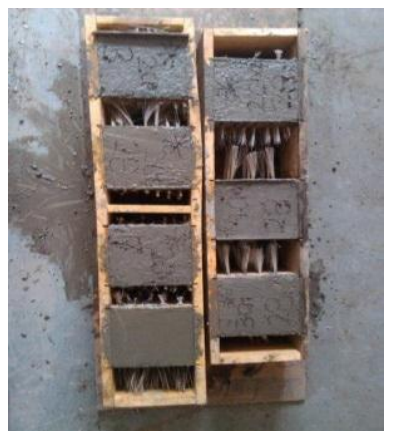

Fig.(3) 


\section{International Journal of Engineering Applied Sciences and Technology, 2019 \\ Vol. 3, Issue 12, ISSN No. 2455-2143, Pages 119-122 \\ Published Online April 2019 in IJEAST (http://www.ijeast.com)}

\section{TESTS}

\section{A) Light transmittance test on LiTraCon-}

Light measuring equipment such as Lux meter, can be used. The light transmittance through the sample can be measured by measuring the current corresponding to the light which can be measured by a photo diode or a Light Dependent Resistors (LDR). The experimental set up is as shown in the Fig(4).

The LDR measures the light transmitted through the sample and converts it into the current, which in this case is measured in milli-amperes (mA). Two readings are taken, one without sample (A1) and one with the sample (A2). The source of light is generally taken as $100 \mathrm{~W}$ incandescent bulbs, a resistance of $100 \Omega$ is applied in the circuit and a uniform DC voltage of $2.5 \mathrm{~V}$ is kept between the circuits. To ensure no light escapes throughout the test, a box made up of plywood is made. The light source is fixed at the top of the box and LDR is placed at the bottom. The sample is placed between source and LDR and test is carried out.

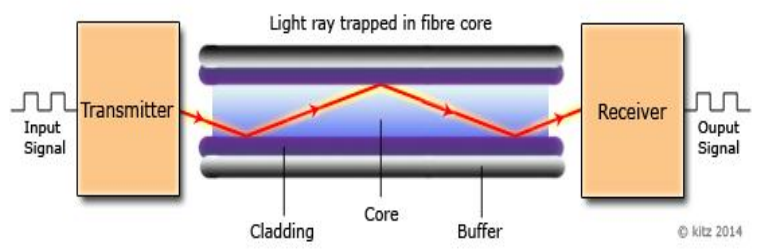

Fig.(4):Experimental setup

The amount of light transmitted is calculated as: Light transmittance $=100-[(\mathrm{A} 1-\mathrm{A} 2) / \mathrm{A} 1] \times 100$

\section{B) Compressive Strength Test on LiTraCon-}

The compressive strength of samples was then determined after measuring the light transmitted by using compressive testing machine and test results were obtained.

\section{C) Flexural Strength on LiTraCon-}

The flexural strength is carried out on a standard prism of size $500 \mathrm{mmx} 100 \mathrm{mmx} 100 \mathrm{~mm}$ and the test results obtained can be compared with that of nominal prism for 7 , 28days respectively.

\section{ADVANTAGES}

a) Energy Consumption can be reduced by utilization of transparent concrete, thus integrating the concept of green building. b) Light transmitting concrete is frost and de-icing resistant which means it works as heat insulators, thus it is more effective in colder regions.

c) Translucent concrete add a deal of security and supervision in places like schools, prisons and so on, where the presence of the people and their actions are seen but not their entire image, thereby protecting their privacy as well.

d) It has good Architectural view and is aesthetically appealing.

\section{VII.DISADVANTAGES}

a) The main disadvantage is that it is very costly because of the optical fibers.

b) It requires skilled labour for installation of optical fibers.

\section{APPLICATIONS}

a) Transparent concrete blocks are best suited for floors and walls.

b) Interior walls, facades, dividing walls, logos and other aesthetic structures can also be made using transparent concrete.

c) Translucent concrete walls can be utilized in restaurants, clubs, and so on.

d) Speed bumps on highways, expressways and sidewalks may be constructed using transparent concrete with lighting underneath that would create more safety for pedestrians during night.

\section{CONCLUSIONS}

a) Litracon achieve utilization and optimization of light, and is independent of the thickness.

b) The light transmission may decrease with usage of Plastic optical fibers but it is economical when compared to glass optical fiber.

c) The light transmission of litracon block increases with the increase in the percentage of optical fiber.

d) As the percentage of optical fiber increases, the weight of the Litracon block decreases.

e) As the diameter of the optical fiber increases, the weight of the Litracon block decreases.

f) The compressive strength of light transmitting concrete is slightly reduced than that of conventional concrete. 


\section{International Journal of Engineering Applied Sciences and Technology, 2019 \\ Vol. 3, Issue 12, ISSN No. 2455-2143, Pages 119-122 \\ Published Online April 2019 in IJEAST (http://www.ijeast.com)}

g) Flexural Strength of optimum percent of litracon prism increases when compared to conventional concrete.

\section{REFERENCES}

[1] Ravikumar.N, Dharsika.S, (2018), "Experimental Study on Light Transparency of Concrete by Using Optical Fiber", IJSES, ( pp. 01-04).

[2] Anish Tayal.Er, Sourabh Sharma.Er, (2017)“A Literature Review on the Transparent or Translucent Concrete", IJLTET, ( pp. 302-304).

[3] Akshaya B Kamdi, (2013) "Transparent Concrete as a Green Material for Building”, IJSCER,(pp. 172-175).

[4] Ravivarman.S, Mageswari.M, Kanagalakshmi.A.S, (2015) "Experimental study of LiTraCon", IOSRJMCE, (pp. 07-13)

[5] Harika.BR, Ajay Kumar Reddy, (2017)“ Low Cost Translucent Concrete”, IJMETMR,(pp. 351-359).

[6] Bharti Sharma, Amarnath Gupta(2018), "An Overview on Transparent Concrete", IRJET, (pp. 2040-2045)

[7] Yamini Nirmal.B, Mr.Nehemiya.K, Sri Giri Prasad.G, "Study on Mechanical Properties of Light Transmitting Concrete", IRJET, Volume: 04 Issue: 07,July -2017.

[8] Nimitha Vijayaraghavan,(2016) "Properties of Concrete Cube by Using Optical Fibers”, IJRAET,(pp. 90-92).
[9] Gurpreet Singh, Dhande Uttam, Adurkar Ajit, Prof. Mrs Sayyed.G.A,(2016) "Experimental Investigation of LiTraCon by using Plastic Optical Fiber", IJLRET, (pp.25-29).

[10] Juan Shen and Zhi Zhou (2013)," Some Progress on Smart Transparent Concrete", Pacific Science Review, (pp. 51 55).

[11] Siddhesh Gahrana, Vivek Raj, Sudhanshu Chouhan, Snesh Krishnia (2018) “Application Of Transparent Concrete In Green Construction” IJSTR,(pp. 119-122).

[12] Padma Bhushan.M.N.V, Johnson.D, Md. Afzal Basheer Pasha, Ms.Prasanthi.K(2013)," Optical Fibers' in the Modeling of Translucent Concrete Blocks," IJERA,(pp. 13-17).

[13] Nadeem Gulzar Shahmir, Manzoor Ahmad Tantray (2019)," A Promising Light Weight Future Material Translucent Concrete", IJRTE ,(pp. 372-374).

[14] Jadhav Sunil, Kadlag Amol, Kawade Chetan, Talekar Pravin (2015)," A Study on Translucent Concrete Product and Its Properties by Using Optical Fibers", IJMER,(pp. 53-57).

[15] Rasvir Singh, Sunil Priyadarshi (2019)," Transparent Concrete", IJRESM,(pp. 326-329). 